\title{
Serum Fructosamine and Glycosylated Hemoglobin in Monitoring the Glycemic Control in Gestational Diabetes Mellitus
}

\author{
Mohamed M. Farghali ${ }^{1,2}$, Ali M. Mahmoud ${ }^{3}$, Ghassan Baidas ${ }^{4}$, Mohamed M. Khalafalla $^{5}$, \\ Ibrahim A. Abdelazim ${ }^{1,6^{*}}$, Shikanova Svetlana ${ }^{7}$ \\ ${ }^{1}$ Department of Obstetrics and Gynecology, Ain Shams University, Cairo, Egypt \\ ${ }^{2}$ Department of Obstetrics and Gynecology, Al-Sabah Maternity Hospital, Sabah Area, Kuwait \\ ${ }^{3}$ Department of Internal Medicine, Al-Azahar University, Cairo, Egypt \\ ${ }^{4}$ Department of Internal Medicine, Al-Sabah Maternity Hospital, Sabah Area, Kuwait \\ ${ }^{5}$ Department of Obstetrics and Gynecology, Menofia University, Menofia, Egypt \\ ${ }^{6}$ Department of Obstetrics and Gynecology, Ahmadi Hospital, KOC, Ahmadi, Kuwait \\ ${ }^{7}$ Department of Obstetrics and Gynecology, Marat Ospanov, West Kazakhstan State Medical University (WKSMU), Aktobe, \\ Kazakhstan \\ Email: mohamedfarghali@hotmail.com, Ali_196620@yahoo.com, g-Baidas@hotmail.com, khalafalah2006@yahoo.com, \\ *dr.ibrahimanwar@gmail.com, Shik.sv@mail.ru
}

How to cite this paper: Farghali, M.M., Mahmoud, A.M., Baidas, G., Khalafalla, M.M., Abdelazim, I.A. and Svetlana, S. (2018) Serum Fructosamine and Glycosylated Hemoglobin in Monitoring the Glycemic Control in Gestational Diabetes Mellitus. Open Journal of Obstetrics and Gynecology, 8, 630-645.

https://doi.org/10.4236/ojog.2018.86068

Received: May 29, 2018

Accepted: June 22, 2018

Published: June 25, 2018

Copyright $\odot 2018$ by authors and Scientific Research Publishing Inc. This work is licensed under the Creative Commons Attribution International License (CC BY 4.0).

http://creativecommons.org/licenses/by/4.0/

(c) (i) Open Access

\begin{abstract}
Background: Diabetes mellitus complicates $1 \%-2 \%$ of all pregnancies, and associates with high perinatal morbidity. Gestational diabetes mellitus (GDM) is treatable condition, and women who have adequate glycemic control during pregnancy can effectively decrease the adverse outcomes of GDM. Objectives: This study was designed to compare the serum fructosamine, and the glycosylated hemoglobin (HbAlc), in monitoring the glycemic control in GDM. Patients and Methods: 1516 women with GDM included, and were advised for dietary modification to achieve proper glycemic control. If the target glucose levels were not reached by the diet regimen or by the dietary modification, insulin was prescribed for the studied women. The average values of the pre- and post-prandial glucose levels were calculated, and the insulin doses were adjusted to achieve the target glucose values during the antenatal visits. $\mathrm{HbA1c}$, and fructosamine were measured to assess the glycemic control for the studied women. Results: The fructosamine, and the HbAlc were significantly high in the uncontrolled GDM compared to controlled group, and there was positive significant correlation between fractuosamine, and $\mathrm{HbAlc}$ in monitoring the glycemic control in GDM $(r=0.93$, and $P=0.001)$. The Odds ratio (OR), and relative risk (RR) analysis for the current pregnancy outcome showed that the polyhydramnios (OR 3.8; RR 3.7), the cesarean de-
\end{abstract}


livery (OR 1.7; RR 1.4), the fetal macrosomia (OR 6.4; RR 6.3), the fetal anomalies (OR 6.5; RR 6.4), and the (IUFD) intrauterine fetal death (OR 8.7; RR 8.6) were significantly high in uncontrolled GDM group. In addition, the (NND) neonatal death (OR 11.6; RR 11.4), the neonatal intensive care unit (NICU) admission (OR 3.1; RR 2.9), the neonatal hyperbilirubinemia (OR 3.7; RR 3.6), the transient tachypnea of the newborn (OR 3.1; RR 2.9), and the neonatal hypoglycemia (OR 3.5; RR 3.4) were significantly high in uncontrolled GDM group. Conclusion: Fructosamine assay is simple, reliable, useful indicator for the glycemic control in GDM over the last 2 - 3 weeks, and poor glycemic control in GDM increases the risk of adverse maternal and neonatal outcomes.

\section{Keywords}

Serum Fructosamine, HbA1c, GDM

\section{Introduction}

Diabetes mellitus (DM) complicates $1 \%-2 \%$ of pregnancies, and associates with high perinatal morbidity [1]. Gestational diabetes mellitus (GDM) defined as a glucose intolerance of any degree discovered for the first time during pregnancy [2].

Infants of diabetic mothers exposed to adverse outcomes including: metabolic, respiratory, cardiac disorders, perinatal asphyxia, and birth traumas [3].

Macrosomia is the most constant consequence of diabetes, and its severity is influenced by the maternal blood glucose levels.

Pedersen-FreinkeP $s$, suggested that the fetal macrosomia in DM is due to the trans-placental transfer of maternal glucose, which stimulates the release of insulin by fetal pancreatic beta cells [4]. Insulin increases the insulin-like growth factors, with subsequent fetal macrosomia.

Ostlund et al., and Ong et al., demonstrated definite link between maternal glycemia, and neonatal macrosomia, and/or fetal fat mass [5] [6].

A recent analysis of data from WHO's Global Survey on maternal, and perinatal outcomes in 23 developing countries described the prevalence of macrosomia, as one of the main complications of maternal diabetes [7].

The Hyperglycemia and Adverse Pregnancy Outcome (HAPO) study showed positive association between maternal glycemia, fetal hyperinsulinism, and fetal body weight [8] [9].

The infant of diabetic mother is at risk of transient hyperinsulinism, with subsequent neonatal hypoglycemia [10]. Crowther et al., and Landon et al., reported that the rate of intravenously treated hypoglycemia babies of diabetic mothers was between 5\% - 7\% [11] [12].

GDM associated with risk of neonatal persistent pulmonary hypertension [13] and myocardial hypertrophy has been reported in both pre-gestational diabetes and GDM with a wide range of frequencies (between 25\% - 75\%) [14]. 
The most common cardiac malformations reported in infants of diabetic mothers are transposition of the great arteries, hypoplastic left heart syndrome, and ventricular septal defects [15].

The risk of perinatal asphyxia in GDM (5-min Apgar score < 7) was 1\% - 2\% in a study including more than thousand neonates of GDM mothers [11]. In another study, the reported umbilical arterial $\mathrm{pH}<7.2$ in GDM group was $15 \%$, compared to non-diabetic controls [16].

Poor maternal glycemic control increases the risk of adverse neonatal outcomes, and perinatal morbidity [3]. GDM is treatable condition, and women who have adequate glycemic control during pregnancy, can effectively decrease the adverse outcomes of GDM [17].

Fructosamine is a marker of glucose control reflecting the average glycemic level over the preceding $2-3$ weeks [18]. Consequently, fructosamine may be more appropriate marker for monitoring early response to treatment [19] [20]. Fructosamine has been proposed to monitor the glycemic control for diabetes during pregnancy [21], in low-resource countries [22], and countries with high prevalence of sickle cell diseases, and sickle cell traits [23] [24]. So, this prospective study was designed to compare the serum fructosamine, and the glycosylated hemoglobin ( $\mathrm{HbAlc}$ ), in monitoring the glycemic control in GDM, and to evaluate the perinatal morbidity associated with GDM.

\section{Patients and Methods}

This prospective comparative study was conducted in the Obstetrics department of Al-Sabah Maternity Hospital, Kuwait over 3 years (January 2014 to January 2017), after approval of the study by the institute ethical committee.

Women between 20 - 35 years, and 24 - 36 gestational weeks, singleton pregnancy, diagnosed with GDM according to the International Association of Diabetes, and Pregnancy Study Groups (IADPSG) criteria (fasting blood sugar (FBS) $\geq 5.6 \mathrm{mmol} / \mathrm{dl}(126 \mathrm{mg} / \mathrm{dl}$; random blood sugar $(\mathrm{RBS}) \geq 11.1 \mathrm{mmol} / \mathrm{dl}$ $(200 \mathrm{mg} / \mathrm{dl})$, and $\mathrm{HbAlC} \geq 6.5 \%)$ included in this study after informed written consent.

Pregnant women with hypertensive, cardiac or thyroid disorders or refused to participate were excluded from this study. Pregnant women with established DM type 1 or 2 or renal disorders that can affect serum protein levels (nephrotic syndrome, liver cirrhosis) were also excluded from the study.

The studied women subject to thorough history including; the age, parity, and gestational age at the diagnosis of GDM, family history of DM, previous history of intrauterine fetal death (IUFD), macrocosmic babies, neonatal death (NND), and/or recurrent miscarriages (RMs). The calculation of the body mass index (BMI) for the studied women was followed by baseline investigations according to the hospital protocol (complete blood picture (CBC), liver, and kidney function tests).

Studied women were advised for dietary modifications, and nutritional in- 
structions of three meals, and three snacks daily with pre-designed diets according to their body weight. Total calories/day were calculated according to 30 - 35 $\mathrm{cal} / \mathrm{kg}$ of the body weight, and diet charts were given to the studied women. If the target blood glucose levels for glycemic control (FBS $\leq 100 \mathrm{mg} / \mathrm{dl}(5.5$ $\mathrm{mmol} / \mathrm{l})$, and postprandial blood glucose (1.5 hours after meals) of $\leq 126 \mathrm{mg} / \mathrm{dl}$ $(7 \mathrm{mmol} / \mathrm{l})$ ) were not reached by the diet regimens. Insulin was prescribed for the studied women to achieve the desired glycemic controls (combination of short, and intermediate acting human insulin) twice daily (before breakfast, and before dinner) or as multiple injections (short acting insulin before meals, and intermediate acting at bed-time). The insulin doses were calculated according to the body weight, and the gestational age; $\left(0.6 \mathrm{IU} / \mathrm{kg}\right.$ in $1^{\text {st }}$ trimester, $0.7 \mathrm{IU} / \mathrm{kg}$ in $2^{\text {nd }}$ trimester, $0.8 \mathrm{IU} / \mathrm{kg}$ from 28 - 32 weeks, $0.9 \mathrm{IU} / \mathrm{kg}$ from $32-36$ weeks, and 1 unit/kg from 36 weeks onwards).

Studied women were given supplement of iron, calcium, vitamin $B_{12}$ and folic acid, with follow-up in the ante-natal clinics every 2 weeks according to the hospital protocol, and fetal well-being assessment using trans-abdominal ultrasound scan monthly after 28 weeks. The time and mode of deliveries were decided for the studied women according to the hospital protocol. Studied women were advised to follow the self-blood glucose monitoring (SBGM), and to maintain a written and/or electronic record of their blood glucose levels. Women who could not monitor, and record their blood glucose levels were admitted in the day-care unit for blood glucose monitoring, and the blood sugar series (BSS) were done 6 times/day (fasting, 2 hours post-breakfast, pre-lunch, 2 hours post-lunch, pre-dinner, 2 hours post-dinner). At each ante-natal visit the average values of the pre-and post-prandial blood glucose were calculated for the studied woman, and the insulin doses were adjusted to achieve pre-prandial target glucose values of $9-130 \mathrm{mg} / \mathrm{dl}(5-7.2 \mathrm{mmol} / \mathrm{l})$, and post-prandial target glucose values of 9 $180 \mathrm{mg} / \mathrm{dl}$ (5 - $10.0 \mathrm{mmol} / \mathrm{l})$. The frequencies of hypoglycemia were assessed by reviewing the patients' records (hypoglycemia defined as documented blood glucose level $<70 \mathrm{mg} / \mathrm{dl}(3.9 \mathrm{mmol} / \mathrm{l}) \pm$ symptoms $)$. HbAlc was measured for the studied women monthly by radioimmunoassay to assess the glycemic control (normal HbAlc $<7 \%$, while, HbAlc $>9 \%$ equals poor control). Fructosamine was measured every 2 weeks bichromatically as an end-point reaction based on the ability of glycated proteins to reduce nitro blue tetrazolium method (NBT) in an alkaline solution [17].

One thousand-five hundred and sixty five (1565) women with GDM recruited at the beginning of this study, and the study was completed with final analysis of the data for 1516 women ( 49 women were not included in the final analysis of the study because of preterm labor, incomplete records, delivery outside the hospital, and travelling) Figure 1.

The studied women classified into; controlled GDM (1123 women), and uncontrolled GDM (393 women) to compare the serum fructosamine, and the glycosylated hemoglobin (HbAlc), in monitoring the glycemic control in GDM, 


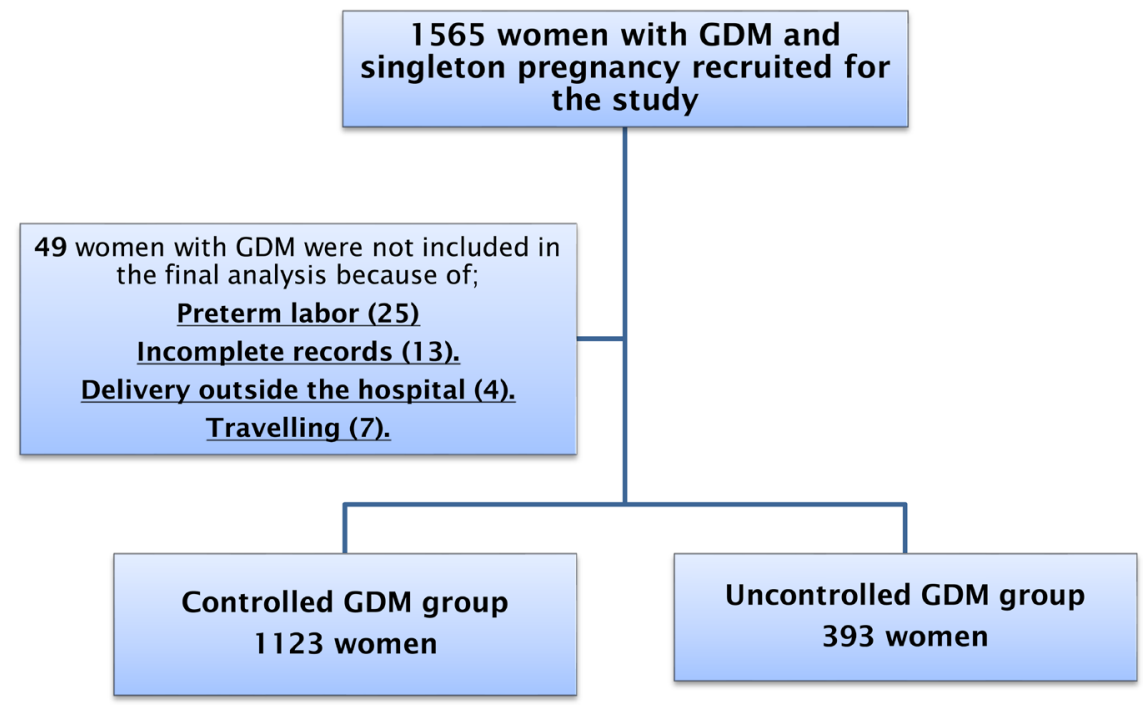

GDM: Gestational diabetes mellitus.

Figure 1. The study follow-chart.

and to evaluate the perinatal morbidity associated with GDM.

Sample size: The required sample size was calculated using G Power software version 3.17 for sample size calculation (Heinrich Heine Universität; Düsseldorf; Germany), setting $\alpha$-error probability at 0.05 , power ( $1-\beta$ error probability) at $0.95 \%$, and effective sample size $(w)$ at 0.3 . The effective sample includes $>220$ women in two groups (110 in the study group, and 110 controls) needed to produce a statistically acceptable figure.

Statistical analysis: Collected data statistically analyzed using Statistical Package for Social Sciences (SPSS); computer software version 20 (Chicago, IL, USA). Numerical variables were presented as mean, and standard deviation $( \pm \mathrm{SD})$, while categorical variables were presented as number $(\mathrm{n})$ and percentage (\%). Chi-square test $\left(\mathrm{x}^{2}\right)$ was used for comparison between groups as regard qualitative variables, and student $(\mathrm{t})$ test was used for comparison between groups as regard numerical variables. The Odds ratio (OR), and the relative risk (RR) analysis was used to detect the relation between the glycemic control in GDM, and adverse outcomes. Multivariate regression analysis was used to detect the relation between fructosamine, and HbAlc in monitoring the glycemic control in GDM. $P$-value $<0.05$ considered statistically significant.

\section{Results}

One thousand-five hundred and sixty five (1565) women with GDM recruited at the beginning of this study, and the study was completed with final analysis of the data for 1516 women (1123 controlled GDM, and 393 uncontrolled GDM). There was no significant difference between the two studied groups regarding the maternal age, and the gestational age ( $31.5 \pm 4.8$ years, and $28.4 \pm 2.5$ weeks; respectively for the controlled GDM group versus $29.3 \pm 5.6$ years, and $29.3 \pm$ 2.9 weeks; respectively for the uncontrolled group). 
While, the mean BMI was significantly high in the uncontrolled GDM group compared to the controlled group $\left(30.1 \pm 5.5\right.$ versus $28.2 \pm 6.1 \mathrm{Kg} / \mathrm{m}^{2}$; respectively, $P=0.007$ ). The previous history of intra-uterine fetal death (IUFD), and fetal macrosomia was significantly high in the uncontrolled GDM group (15 (3.8\%) and 12 (3.1\%); respectively) compared to controlled group (11 (0.98\%) and $7(0.62 \%)$; respectively), ( $P=0.0002$ and 0.0002 ; respectively). The previous history of neonatal death (NND), and recurrent miscarriages (RMs) was significantly high in the uncontrolled GDM group $(9$ (2.3\%) and 17 (4.3\%); respectively) compared to controlled group (3 $(0.27 \%)$ and $13(1.15 \%)$; respectively), $(P=$ 0.0001 and 0.0001 ; respectively) Table 1 .

The Odds ratio (OR), and relative risk (RR) analysis for the previous pregnancies outcome showed that; the IUFD (OR 4.0 (95\%CI; 1 - 0.8), $P=0.0005$; RR 3.8 (95\%CI; $1-0.4), P=0.0005$ ), and the fetal macrosomia (OR 5.0 (95\%CI; 1.9 12.8), $P=0.0008$; RR 4.8 (95\%CI; $1.9-12.4), P=0.0008$ ) were significantly high in the uncontrolled GDM group. In addition; the NND (OR 8.7 (95\%CI; 2.4 32.5), $P=0.001$; RR 8.5 (95\%CI; $2.3-31.5$ ), $P=0.001$ ), and RMs (OR 3.8 (95\%CI; 1.8 - 8.0), $P=0.0003$; RR 3.7 (95\%CI; $1.8-7.6), P=0.0003$ ) were significantly high in the uncontrolled GDM group Table 2.

The fasting blood glucose $(7.6 \pm 6.1 \mathrm{mmol} / \mathrm{l}$ versus $5.8 \pm 6.8$; respectively, $P=$ $0.005)$, the pre-prandial glucose $(8.3 \pm 2.2 \mathrm{mmol} / \mathrm{l}$ versus $6.2 \pm 2.9$; respectively, $P=0.04)$, and the post-prandial glucose $(10.5 \pm 3.1 \mathrm{mmol} / \mathrm{l}$ versus $9.2 \pm 3.6$; respectively, $P=0.002$ ) were significantly high in the uncontrolled GDM group

Table 1. The demographic data of the two studied group, and the outcome of the previous pregnancies.

\begin{tabular}{|c|c|c|c|}
\hline Variables & $\begin{array}{l}\text { Controlled GDM } \\
\text { (1123 women) }\end{array}$ & $\begin{array}{l}\text { Uncontrolled GDM } \\
\text { (393 women) }\end{array}$ & $\begin{array}{c}P \text { value (95\% } \\
\text { Confidence Interval) }\end{array}$ \\
\hline Maternal age (Years) & & & 0.9 \\
\hline Mean \pm SD & $31.5 \pm 4.8$ & $29.3 \pm 5.6$ & $(1.5,2.2,2.8)$ \\
\hline BMI $\left(\mathrm{Kg} / \mathrm{m}^{2}\right)$ & & & $0.007^{\star}$ \\
\hline Mean \pm SD & $28.2 \pm 6.1$ & $30.1 \pm 5.5$ & $(-2.6,-1.9,-1.2)$ \\
\hline Gestational age (Weeks) & & & 0.9 \\
\hline Mean \pm SD & $28.4 \pm 2.5$ & $29.3 \pm 2.9$ & $(-1.2,0.9,-0.6)$ \\
\hline \multicolumn{4}{|l|}{ Previous history of IUFD } \\
\hline Number $(\%)$ & $11(0.98 \%)$ & $15(3.8 \%)$ & $0.0002^{*}$ \\
\hline \multicolumn{4}{|c|}{ Previous history of fetal macrosomia } \\
\hline Number (\%) & $7(0.62 \%)$ & $12(3.1 \%)$ & $0.0002^{*}$ \\
\hline \multicolumn{4}{|l|}{ Previous history of NND } \\
\hline Number $(\%)$ & $3(0.27 \%)$ & $9(2.3 \%)$ & $0.0001^{*}$ \\
\hline \multicolumn{4}{|l|}{ Previous history of RMs } \\
\hline Number $(\%)$ & $13(1.15 \%)$ & $17(4.3 \%)$ & $0.0001^{*}$ \\
\hline
\end{tabular}

*Significant difference. BMI: Body mass index. Chi-square test $\left(\mathrm{X}^{2}\right)$ used for statistical analysis, when data presented as number and \%. Data presented as mean \pm SD (standard deviation), and number and percentage (\%). GDM: gestational diabetes mellitus. IUFD: Intrauterine fetal death. NND: Neonatal deaths. RMS: Recurrent miscarriages. Student $t$ test used for statistical analysis, when data presented as mean \pm SD. 
Table 2. The odds ratio, and the relative risk analysis for the previous pregnancies outcome.

\begin{tabular}{cccc}
\hline Variables & $\begin{array}{c}\text { Positive } \\
\text { outcome }\end{array}$ & $\begin{array}{c}\text { Negative } \\
\text { outcome }\end{array}$ & $\begin{array}{c}\text { Odds ratio (95\%CI) } P \text { value } \\
\text { Relative Risk (95\%CI) } P \text { value }\end{array}$ \\
\hline $\begin{array}{c}\text { Previous history of IUFD } \\
\text { Controlled GDM }\end{array}$ & 11 & 1112 & $4.0(1.8-8.8) 0.0005^{\star}$ \\
Uncontrolled GDM & 15 & 378 & $3.8(1.8-8.4) 0.0005^{\star}$ \\
Previous history of fetal macrosomia & & & \\
Controlled GDM & 7 & 1116 & $5.0(1.9-12.8) 0.0008^{\star}$ \\
Uncontrolled GDM & 12 & 381 & $4.8(1.9-12.4) 0.0008^{\star}$ \\
Previous history of neonatal death & & & $8.7(2.4-32.5) 0.001^{*}$ \\
Controlled GDM & 3 & 1120 & $8.5(2.3-31.5) 0.001^{\star}$ \\
Uncontrolled GDM & 9 & 384 & \\
$\quad$ & & & $3.8(1.8-8.0) 0.0003^{\star}$ \\
Previous history of RMs & 13 & 1110 & $3.7(1.8-7.6) 0.0003^{*}$ \\
Controlled GDM & 17 & 376 & \\
Uncontrolled GDM & & &
\end{tabular}

*Significant difference. $\mathrm{CI}=$ Confidence interval. GDM: gestational diabetes mellitus. IUFD: Intrauterine fetal death. RMS: Recurrent miscarriages.

compared to controlled group. The serum fructosamine $(462.5 \pm 119 \mu \mathrm{mol} / \mathrm{l}$ versus $337.4 \pm 132$; respectively, $P=0.007$ ), and the HbA1c ( $8.4 \pm 5.8$ versus 7.2 \pm 6.6 ; respectively, $P=0.001$ ) were significantly high in the uncontrolled GDM group compared to controlled group Table 3.

The polyhydramnios rate $(17(4.3 \%)$ versus $13(1.16 \%)$; respectively, $P=$ $0.0001)$, and the cesarean delivery rate $(124(31.6 \%)$ versus $238(21.2 \%)$; respectively, $P=0.001$ ), were significantly high in the uncontrolled GDM group compared to the controlled group. The fetal macrosomia (11 (2.8\%) versus 5 (0.45\%); respectively, $P=0.0001)$, the fetal anomalies $(9(2.29 \%)$ versus 4 (0.36\%); respectively, $P=0.0004)$, the IUFD $(9(2.29 \%)$ versus $3(0.27 \%)$; respectively, $P=0.0001)$, and the NND (8 (2.04\%) versus $2(0.18 \%)$; respectively, $P=$ 0.001 ) were significantly high in the uncontrolled GDM group compared to the controlled group.

In addition; the neonatal intensive care unit (NICU) admission (25 (6.36\%) versus 24 (2.14\%); respectively, $P=0.0001)$, the neonatal hyperbilirubinemia (15 (3.05\%) versus $12(1.07 \%)$; respectively, $P=0.0005)$, the transient tachypnea of the newborn (24 (6.1\%) versus 23 (2.05\%); respectively, $P=0.0001)$, and the neonatal hypoglycemia (18 (4.58\%) versus $15(1.34 \%)$; respectively, $P=0.0002)$ were significantly high in the uncontrolled GDM group compared to controlled group Table 3.

The Odds ratio (OR), and relative risk (RR) analysis for the current pregnancy outcome showed that; the polyhydramnios (OR 3.8 (95\%CI; $1.9-8.0$ ), $P=$ 0.0003; RR 3.7 (95\% CI; $1.8-7.6$ ), $P=0.0003$ ), the cesarean delivery (OR 1.7 (95\%CI; $1.3-2.2), P=0.0001$; RR 1.4 (95\%CI; $1.2-1.8), P=0.0001$ ), and the 
Table 3. The blood glucose, fructosamine, $\mathrm{HbAlc}$, and the outcome of the current pregnancy.

\begin{tabular}{|c|c|c|c|}
\hline Variables & $\begin{array}{l}\text { Controlled GDM } \\
\text { (1123 women) }\end{array}$ & $\begin{array}{l}\text { Uncontrolled GDM } \\
\text { (393 women) }\end{array}$ & $\begin{array}{c}P \text { value ( } 95 \% \\
\text { Confidence Interval) }\end{array}$ \\
\hline Fasting blood glucose $(\mathrm{mmol} / \mathrm{l})$ & & & $0.005^{*}$ \\
\hline Mean \pm SD & $5.8 \pm 6.8$ & $7.6 \pm 6.1$ & $(-2.5,-1.8,-1.1)$ \\
\hline Pre-prandial glucose $(\mathrm{mmol} / \mathrm{l})$ & & & $0.04^{*}$ \\
\hline Mean \pm SD & $6.2 \pm 2.9$ & $8.3 \pm 2.2$ & $(-2.4,-2.1,-1.8)$ \\
\hline Postprandial glucose $(\mathrm{mmol} / \mathrm{l})$ & & & $0.0002^{*}$ \\
\hline Mean \pm SD & $9.2 \pm 3.6$ & $10.5 \pm 3.1$ & $(-1.7,-1.3,-0.9)$ \\
\hline Fructosamine $(\mu \mathrm{mol} / \mathrm{l})$ & & & $0.007^{*}$ \\
\hline Mean \pm SD & $337.4 \pm 132$ & $462.5 \pm 119$ & $(-139.2,-125.1,-111)$ \\
\hline HbAlc (\%) & & & $0.001^{*}$ \\
\hline Mean \pm SD & $7.2 \pm 6.6$ & $8.4 \pm 5.8$ & $(-1.9,-1.2,-0.5)$ \\
\hline \multicolumn{4}{|l|}{ Polyhydramnios } \\
\hline Number (\%) & $13(1.16 \%)$ & $17(4.3 \%)$ & $0.0001^{*}$ \\
\hline \multicolumn{4}{|l|}{ Vaginal deliveries } \\
\hline Number (\%) & $885(78.8 \%)$ & $269(68.4 \%)$ & 0.1 \\
\hline \multicolumn{4}{|l|}{ Cesarean deliveries } \\
\hline Number (\%) & $238(21.2 \%)$ & $124(31.6 \%)$ & $0.001^{*}$ \\
\hline \multicolumn{4}{|l|}{ Fetal macrosomia } \\
\hline Number (\%) & $5(0.45 \%)$ & $11(2.8 \%)$ & $0.0001^{*}$ \\
\hline \multicolumn{4}{|l|}{ Fetal anomalies } \\
\hline Number (\%) & $4(0.36 \%)$ & $9(2.29 \%)$ & $0.0004^{*}$ \\
\hline \multicolumn{4}{|l|}{ Intrauterine fetal death } \\
\hline Number (\%) & $3(0.27 \%)$ & $9(2.29 \%)$ & $0.0001^{*}$ \\
\hline \multicolumn{4}{|l|}{ Neonatal death } \\
\hline Number (\%) & $2(0.18 \%)$ & $8(2.04 \%)$ & $0.001^{\star}$ \\
\hline \multicolumn{4}{|l|}{ NICU admission } \\
\hline Number (\%) & $24(2.14 \%)$ & $25(6.36 \%)$ & $0.0001^{*}$ \\
\hline \multicolumn{4}{|l|}{ Neonatal hyperbilirubinemia } \\
\hline Number (\%) & $12(1.07 \%)$ & $15(3.05 \%)$ & $0.0005^{*}$ \\
\hline \multicolumn{4}{|l|}{ Transient tachypnea of the newborn } \\
\hline Number $(\%)$ & $23(2.05 \%)$ & $24(6.1 \%)$ & $0.0001^{*}$ \\
\hline \multicolumn{4}{|l|}{ Neonatal hypoglycemia } \\
\hline Number $(\%)$ & $15(1.34 \%)$ & $18(4.58 \%)$ & $0.0002^{\star}$ \\
\hline
\end{tabular}

${ }^{*}$ Significant difference. Chi-square test $\left(\mathrm{X}^{2}\right)$ used for statistical analysis, when data presented as number and $\%$. Data presented as mean \pm SD (standard deviation), and number and percentage (\%). GDM: gestational diabetes mellitus. HbAlc: Glycosylated hemoglobin. NICU: Neonatal intensive care unit. Postprandial glucose $=1.5$ hours after meals. Pre-prandial glucose $=$ prelaunch, and predinner. Student $t$ test used for statistical analysis, when data presented as mean \pm SD.

fetal macrosomia (OR 6.4 (95\%CI; 2.2 - 18.6), $P=0.0006$; RR 6.3 (95\%CI; 2.2 17.9), $P=0.0006$ ) were significantly high in uncontrolled GDM group.

Also; the fetal anomalies (OR 6.5 (95\%CI; $2.0-21.4$ ), $P=0.001$; RR 6.4 (95\%CI; 1.9 - 20.7), $P=0.001$ ), and IUFD (OR 8.7 (95\%CI; $2.3-32.5$ ), $P=0.001$; 
RR 8.6 (95\%CI; $2.3-31.5), P=0.001)$, NND (OR 11.6 (95\%CI; $2.4-55.0), P=$ 0.002; RR 11.4 (95\%CI; 2.4 - 53.5), $P=0.002$ ), and NICU (OR 3.1 (95\%CI; 1.7 5.5), $P=0.0001$; RR 2.9 (95\%CI; $1.7-5.1), P=0.0001)$, were significantly high in uncontrolled GDM group.

In addition; the neonatal hyperbilirubinemia (OR 3.7 (95\% CI; $1.7-7.9$ ), $P=$ 0.0009 ; RR 3.6 (95\%CI; $1.7-7.5), P=0.0009)$, the transient tachypnea of the newborn (OR 3.1 (95\%CI; 1. - .5), $P=0.0001$; RR 2.9 (95\%CI; 1. - .5), $P=$ 0.0001 ), and the neonatal hypoglycemia (OR 3.5 (95\%CI; $1 .-.1$ ), $P=0.0004$; RR 3.4 (95\%CI; 1.7 - 6.7), $P=0.0003$ ) were significantly high in uncontrolled GDM group Table 4.

Multivariate regression analysis showed positive significant correlation between serum fructosamine, and $\mathrm{HbAlc}$ in monitoring the glycemic control in GDM (correlation factor $r=0.93$, and $\mathrm{P}=0.001$ ) Figure 2 .

\section{Discussion}

Poor maternal glycemic control increases the risk of adverse neonatal outcomes, and perinatal morbidity [3]. GDM is treatable condition, and women who have adequate glycemic control during pregnancy, can effectively decrease the adverse outcomes of GDM [17].

Serum fructosamine has been proposed to monitor the glycemic control for diabetes during pregnancy [21], in low-resource countries [22], and countries with high prevalence of sickle cell disease, and sickle cell traits [23]. However, serum fructosamine is not commonly used to monitor the glycemic control in diabetes as HbA1c [24]. So, this prospective study was designed to compare the serum fructosamine, and the $\mathrm{HbAlc}$, in monitoring the glycemic control in GDM, and to evaluate the perinatal morbidity associated with GDM.

One thousand-five hundred and sixty five (1565) women with GDM recruited at the beginning of this study, and the study completed with final analysis of the data for 1516 women (1123 controlled GDM, and 393 uncontrolled GDM). There was no significant difference between the two studied groups regarding the maternal age, and the gestational age, while, the mean BMI was significantly high in the uncontrolled GDM group compared to the controlled group ( $P=$ 0.007).

Hillier et al., conducted their study to estimate the relation between the maternal weight gain, maternal glucose, and the fetal macrosomia among GDM population, and they concluded that women with abnormal levels of glucose tolerance had greater risk of adverse outcome with weight gain [25]. Hillier et al., in another study concluded that the excessive maternal weight gain is a risk factor for all ranges of glucose intolerance [26].

In this study; the Odds ratio, and relative risk analysis for the previous pregnancies outcome showed that; the IUFD (OR 4.0; RR 3.8), the fetal macrosomia (OR 5.0; RR 4.8), the NND (OR 8.7; RR 8.5), and the RMs (OR 3.8; RR 3.7) were significantly high in the uncontrolled GDM group. The Odds ratio, and relative 
Table 4. The odds ratio, and the relative risk analysis for the current pregnancy outcome.

\begin{tabular}{|c|c|c|c|}
\hline Variables & $\begin{array}{l}\text { Positive } \\
\text { outcome }\end{array}$ & $\begin{array}{l}\text { Negative } \\
\text { outcome }\end{array}$ & $\begin{array}{l}\text { Odds ratio }(95 \% \mathrm{CI}) P \text { value } \\
\text { Relative Risk }(95 \% \mathrm{CI}) P \text { value }\end{array}$ \\
\hline \multicolumn{4}{|l|}{ Polyhydramnios } \\
\hline Controlled GDM & 13 & 1110 & $3.8(1.9-8.0) 0.0003^{*}$ \\
\hline Uncontrolled GDM & 17 & 376 & $3.7(1.8-7.6) 0.0003^{*}$ \\
\hline \multicolumn{4}{|l|}{ Cesarean delivery } \\
\hline Controlled GDM & 238 & 885 & $1.7(1.3-2.2) 0.0001^{\star}$ \\
\hline Uncontrolled GDM & 124 & 269 & $1.4(1.2-1.8) 0.0001^{*}$ \\
\hline \multicolumn{4}{|l|}{ Fetal macrosomia } \\
\hline Controlled GDM & 5 & 1118 & $6.4(2.2-18.6) 0.0006^{*}$ \\
\hline Uncontrolled GDM & 11 & 382 & $6.3(2.2-17.9) 0.0006^{*}$ \\
\hline \multicolumn{4}{|l|}{ Fetal anomalies } \\
\hline Controlled GDM & 4 & 1119 & $6.5(2.0-21.4) 0.001^{*}$ \\
\hline Uncontrolled GDM & 9 & 384 & $6.4(1.9-20.7) 0.001^{\star}$ \\
\hline \multicolumn{4}{|l|}{ Intrauterine fetal death } \\
\hline Controlled GDM & 3 & 1120 & $8.7(2.3-32.5) 0.001^{\star}$ \\
\hline Uncontrolled GDM & 9 & 384 & $8.6(2.3-31.5) 0.001^{*}$ \\
\hline \multicolumn{4}{|l|}{ Neonatal death } \\
\hline Controlled GDM & 2 & 1121 & $11.6(2.4-55.0) 0.002^{*}$ \\
\hline Uncontrolled GDM & 8 & 385 & $11.4(2.4-53.5) 0.002^{*}$ \\
\hline \multicolumn{4}{|l|}{ NICU admission } \\
\hline Controlled GDM & 24 & 1099 & $3.1(1.75-5.5) 0.0001^{*}$ \\
\hline Uncontrolled GDM & 25 & 368 & $2.9(1.7-5.1) 0.0001^{*}$ \\
\hline \multicolumn{4}{|c|}{ Neonatal hyperbilirubinemia } \\
\hline Controlled GDM & 12 & 1111 & $3.7(1.7-7.9) 0.0009^{*}$ \\
\hline Uncontrolled GDM & 15 & 378 & $3.6(1.7-7.5) 0.0009^{*}$ \\
\hline \multicolumn{4}{|c|}{ Transient tachypnea of the newborn } \\
\hline Controlled GDM & 23 & 1100 & $3.1(1.7-5.5) 0.0001^{*}$ \\
\hline Uncontrolled GDM & 24 & 369 & $2.9(1.7-5.2) 0.0001^{*}$ \\
\hline \multicolumn{4}{|l|}{ Neonatal hypoglycemia } \\
\hline Controlled GDM & 15 & 1108 & $3.5(1.7-7.1) 0.0004^{*}$ \\
\hline Uncontrolled GDM & 18 & 375 & $3.4(1.7-6.7) 0.0003^{*}$ \\
\hline
\end{tabular}

*Significant difference. $\mathrm{CI}=$ Confidence interval. GDM: gestational diabetes mellitus. NICU: Neonatal intensive care unit.

risk analysis for the current pregnancy outcome showed that; the polyhydramnios (OR 3.8; RR 3.7), the cesarean delivery (OR 1.7; RR 1.4), the fetal macrosomia (OR 6.4; RR 6.3), the fetal anomalies (OR 6.5; RR 6.4), and the IUFD (OR 8.7; RR 8.6) were significantly high in uncontrolled GDM group. In addition; the NND (OR 11.6; RR 11.4), the NICU (OR 3.1; RR 2.9), the neonatal hyperbilirubinemia 


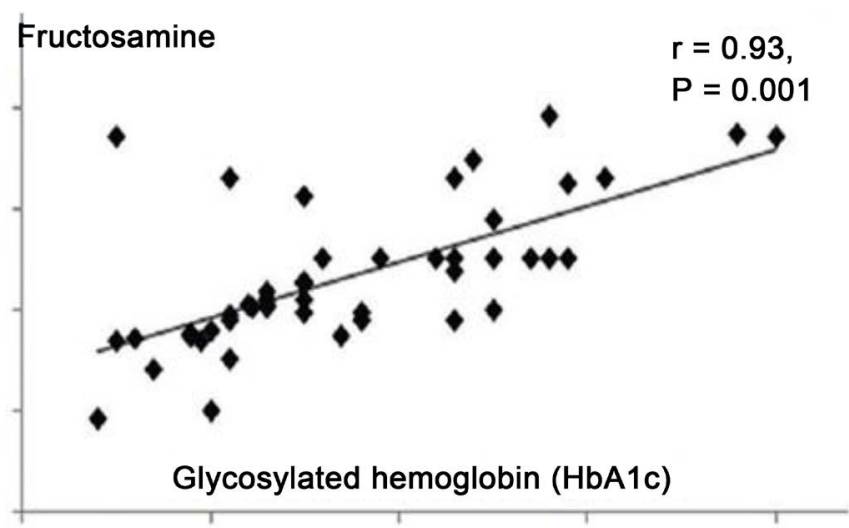

Figure 2. Correlation between $\mathrm{HbAlc}$, and fructosamine in monitoring the glycemic control in GDM.

(OR 3.7; RR 3.6), the transient tachypnea of the newborn (OR 3.1; RR 2.9), and the neonatal hypoglycemia (OR 3.5; RR 3.4) were significantly high in uncontrolled GDM group.

The HAPO study reported correlations between fasting, 1-h, and 2-h glucose levels, and adverse outcomes, including increased birth weight, cesarean section, and neonatal hypoglycemia [8] [9].

Ostlund et al., and Ong et al., demonstrated definite link between maternal glycemia, and neonatal macrosomia, and/or fetal fat mass [5] [6].

A WHO's Global Survey in 23 developing countries described the prevalence of macrosomia, as one of the main complications of maternal diabetes [7].

Matthew et al., concluded that the treatment of GDM substantially reduced macrosomia at birth [27]. Singla et al., concluded that GDM should be treated aggressively, and women with GDM are at increased risk for adverse perinatal outcomes [28].

In addition; Kc et al., reported that the fetal macrosomia is a common adverse outcome of GDM if unrecognized and untreated properly [29]. Kc et al., concluded that the fetal macrosomia increases the risk of shoulder dystocia, clavicle fractures, brachial plexus injury, NICU admissions, cesarean delivery, postpartum hemorrhage, and vaginal lacerations [29].

Kerényi et al., found strong association between large for gestational age (LGA), and maternal fasting glucose, compared to weak association between LGA, and 2-h post-prandial glucose in a population-based screening program of GDM [30].

Kitzmiller et al., reported 7.6\% respiratory distress syndrome (RDS), 9\% major congenital anomalies, $7 \%$ transient tachypnea of the newborn, $22 \%$ hypokalemia, 19\% hyperbilirubinemia, and $47 \%$ hypoglycemia as perinatal morbidity in diabetic pregnant women [31].

Crowther et al., and Landon et al., reported that the rate of intravenously treated hypoglycemia babies of diabetic mothers was between 5\% - 7\% [11] [12].

Mannan et al., studied 100 cases of DM during pregnancy (76\% GDM), and reported; $2 \%$ spontaneous miscarriage, $2 \%$ IUFD, $58 \%$ cesarean section (CS) 
rate, 4\% NND [32]. Mannan et al., concluded that early detection, strict glycemic control, delivery with intensive intrapartum monitoring, and excellent neonatal facilities can result in good maternal and fetal outcome [32].

Crowther et al., reported 1\% - 2\% risk of perinatal asphyxia (5-min Apgar score < 7) in GDM [11], and Langer et al., reported an umbilical arterial $\mathrm{pH}<$ 7.2 in $15 \%$ of GDM group, compared to non-diabetic controls [16].

In this study; the multivariate regression analysis showed positive significant correlation between serum fructosamine, and $\mathrm{HbA} 1 \mathrm{c}$ in monitoring the glycemic control in GDM $(r=0.93 ; P=0.001)$.

Since, the hemoglobin life span is closer to 6 - 8 weeks, and the HbAlc reflects the average glucose concentration over the last $6-8$ weeks [33]. HbA1c assay is not suitable to assess the glycemic control in diabetic pregnant women, with short red blood cells (RBCs) lifespan [34]. Vitamins C and E have been reported to lower HbAlc measurements, possibly by inhibiting glycation. Concomitant use of drugs to treat patients with malignancies, human immunodeficiency virus or hepatitis $\mathrm{C}$ virus infection, may have a glycated hemoglobin lowering effect, with false negative result in the glycemic control.

In addition; alcoholism, lipidemia, and chronic ingestion of salicylates may also reduce the level of HbA1c [35]. HbA1c higher levels can be seen in people with a longer RBCs life span, and people with vitamin $B_{12}$ or folate deficiency.

Kilpatrick et al., showed evidence of wide fluctuations in HbAlc between individuals that are unrelated to glycemic status, suggesting that there are "low glycators" and "high glycators" [36].

Fructosamine reflects the short-term diabetic control, and its assay requires small sample volume, and the results are resistant to storage, and heat [17].

Fructosamine reflects the short-term diabetic control, and combination of fructosamine to $\mathrm{HbAlc}$ gives a dynamic advantage of increasing the glycemic control in GDM.

In addition; Macdonald et al., suggested that the fructosamine levels are useful if routinely used to monitor the glycemic control in diabetic practice [37].

This study concluded that the fructosamine assay was simple, reliable, useful indicator for glycemic control over the last 2 - 3 weeks in GDM, and there was positive correlation between fructosamine, and $\mathrm{HbA} 1 \mathrm{c}$ in monitoring the glycemic control in GDM. In addition; this study concluded that poor glycemic control in women with GDM increases the risk of adverse maternal (polyhydramnios, and cesarean delivery rates), and neonatal outcomes (fetal macrosomia, fetal anomalies, IUFD, NND, and NICU admissions).

The strength of this study is coming from the prospective comparative nature of the study, and inclusion of large number of women with GDM (1516) over the period of 3 years (2014 to 2017).

Women refused to participate, incomplete records were the limitations faced during conduction of this study. Further studies needed to confirm the value of fructosamine in monitoring the glycemic control for diabetes during pregnancy, 
especially in low-resource countries, and countries with high prevalence of sickle cell diseases, and sickle cell traits. In addition; national, and international programs needed to increase the awareness of diabetic women that strict glycemic control, and delivery in tertiary centers with proper neonatal facilities can reduce the adverse fetal, and maternal outcomes.

\section{Conclusion}

Fructosamine assay is simple, reliable, useful indicator for glycemic control over the last $2-3$ weeks, and there is positive correlation between fructosamine, and HbA1c in monitoring the glycemic control in GDM. Poor glycemic control in women with GDM increases the risk of adverse maternal and neonatal outcomes.

\section{Acknowledgements}

Authors are grateful to women agreed to participate in this study.

\section{Conflict of Interest}

Authors declared no conflict of interest related to this study.

\section{Disclosure}

The study funded by the authors themselves.

\section{References}

[1] Higgins, M. and Mc Auliffe, F. (2010) A Review of Maternal and Fetal Growth Factors in Diabetic Pregnancy. Current Diabetes Reviews, 6, 116-125. https://doi.org/10.2174/157339910790909431

[2] Roglic, G. (2009) Diabetes in Women: The Global Perspective. International Journal of Gynaecology \& Obstetrics, 104, S11-S13. https://doi.org/10.1016/j.ijgo.2008.11.022

[3] Mitanchez, D., Yzydorczyk, C. and Simeoni, U. (2015) What Neonatal Complications Should the Pediatrician Be Aware of in Case of Maternal Gestational Diabetes? World Journal of Diabetes, 6, 734-743. https://doi.org/10.4239/wjd.v6.i5.734

[4] Pedersen, J. (1954) Weight and Length at Birth of Infants of Diabetic Mothers. European Journal of Endocrinology, 16, 330-342. https://doi.org/10.1530/acta.0.0160330

[5] Ostlund, I., Hanson, U., Björklund, A., Hjertberg, R., Eva, N., Nordlander, E., Swahn, M.L. and Wager, J. (2003) Maternal and Fetal Outcomes If Gestational Impaired Glucose Tolerance Is Not Treated. Diabetes Care, 26, 2107-2111. https://doi.org/10.2337/diacare.26.7.2107

[6] Ong, K.K., Diderholm, B., Salzano, G., Wingate, D., Hughes, I.A., MacDougall, J., Acerini, C.L. and Dunger, D.B. (2008) Pregnancy Insulin, Glucose, and BMI Contribute to Birth Outcomes in Nondiabetic Mothers. Diabetes Care, 31, 2193-2197. https://doi.org/10.2337/dc08-1111

[7] Koyanagi, A., Zhang, J., Dagvadorj, A., Hirayama, F., Shibuya, K., Souza, J.P. and Gülmezoglu, A.M. (2013) Macrosomia in 23 Developing Countries: An Analysis of 
a Multicountry, Facility-Based, Cross-Sectional Survey. Lancet, 381, 476-483. https://doi.org/10.1016/S0140-6736(12)61605-5

[8] HAPO Study Cooperative Research Group, Metzger, B.E., Lowe, L.P., Dyer, A.R., Trimble, E.R., Chaovarindr, U., Coustan, D.R., Hadden, D.R., McCance, D.R., Hod, M., McIntyre, H.D., Oats, J.J., Persson, B., Rogers, M.S. and Sacks, D.A. (2008) Hyperglycemia and Adverse Pregnancy Outcomes. New England Journal of Medicine, 358, 1991-2002. https://doi.org/10.1056/NEJMoa0707943

[9] HAPO Study Cooperative Research Group (2009) Hyperglycemia and Adverse Pregnancy Outcome (HAPO) Study: Associations with Neonatal Anthropometrics. Diabetes, 58, 453-459. https://doi.org/10.2337/db08-1112

[10] Hawdon, J.M. (2011) Babies Born after Diabetes in Pregnancy: What Are the Shortand Long-Term Risks and How Can We Minimise Them? Review. Best Practice \& Research Clinical Obstetrics \& Gynaecology, 25, 91-104. https://doi.org/10.1016/j.bpobgyn.2010.10.005

[11] Crowther, C.A., Hiller, J.E., Moss, J.R., McPhee, A.J., Jeffries, W.S. and Robinson, J.S. (2005) Australian Carbohydrate Intolerance Study in Pregnant Women (ACHOIS) Trial Group. Effect of Treatment of Gestational Diabetes Mellitus on Pregnancy Outcomes. New England Journal of Medicine, 352, 2477-2486. https://doi.org/10.1056/NEJMoa042973

[12] Landon, M.B., Spong, C.Y., Thom, E., Carpenter, M.W., Ramin, S.M., Casey, B., Wapner, R.J., Varner, M.W., Rouse, D.J., Thorp Jr, J.M., Sciscione, A., Catalano, P., Harper, M., Saade, G., Lain, K.Y., Sorokin, Y., Peaceman, A.M., Tolosa, J.E. and Anderson, G.B. (2009) Eunice Kennedy Shriver National Institute of Child Health and Human Development Maternal-Fetal Medicine Units Network. A Multicenter, Randomized Trial of Treatment for Mild Gestational Diabetes. New England Journal of Medicine, 361, 1339-1348. https://doi.org/10.1056/NEJMoa0902430

[13] Hernández-Díaz, S., Van Marter, L.J., Werler, M.M., Louik, C. and Mitchell, A.A. (2007) Risk Factors for Persistent Pulmonary Hypertension of the Newborn. Pediatrics, 120, e272-e282. https://doi.org/10.1542/peds.2006-3037

[14] Oberhoffer, R., Högel, J., Stoz, F., Kohne, E. and Lang, D. (1997) Cardiac and Extracardiac Complications in Infants of Diabetic Mothers and Their Relation to Parameters of Carbohydrate Metabolism. Eur $J$ Pediatr., 156, 262-265. https://doi.org/10.1007/s004310050596

[15] Corrigan, N., Brazil, D.P. and McAuliffe, F. (2009) Fetal Cardiac Effects of Maternal Hyperglycemia during Pregnancy. Review. Birth Defects Research Part A Clinical and Molecular Teratology, 85, 523-530. https://doi.org/10.1002/bdra.20567

[16] Langer, O., Yogev, Y., Most, O. and Xenakis, E.M. (2005) Gestational Diabetes: The Consequences of Not Treating. American Journal of Obstetrics \& Gynecology, 192, 989-997. https://doi.org/10.1016/j.ajog.2004.11.039

[17] Ayyappan, S., Philips, S., Kumar, C.K., Vaithiyanandane, V. and Sasikala, C. (2015) Serum Fructosamine a Better Indicator than Glycated Hemoglobin for Monitoring Gestational Diabetes Mellitus. Journal of Pharmacy and Bioallied Sciences, 7, S32-S34. https://doi.org/10.4103/0975-7406.155786

[18] Nansseu, J.R.N., Fokom-Domgue, J., Noubiap, J.J.N., Balti, E.V., Sobngwi, E. and Kengne, A.P. (2015) Fructosamine Measurement for Diabetes Mellitus Diagnosis and Monitoring: A Systematic Review and Meta-Analysis Protocol. BMJ Open, 5, e007689. https://doi.org/10.1136/bmjopen-2015-007689

[19] Dafallah, A.A., Eskandarani, H., Rehaimi, A., al-Ali, A.K., Elbashir, A.M. and Saba, R. (1994) Fructosamine in HbS and G6PD-Deficient Saudi Arabs in the Eastern 
Province of Saudi Arabia. British Journal of Biomedical Science, 51, 332-335.

[20] Koga, M., Hashimoto, K., Murai, J., Saito, H., Mukai, M., Ikegame, K., Ogawa, H. and Kasayama, S. (2011) Usefulness of Glycated Albumin as an Indicator of Glycemic Control Status in Patients with Hemolytic Anemia. Clinica Chimica Acta, 412, 253-257. https://doi.org/10.1016/j.cca.2010.10.014

[21] Hughes, P.F., Agarwal, M., Newman, P. and Morrison, J. (1995) An Evaluation of Fructosamine Estimation in Screening for Gestational Diabetes Mellitus. Diabetic Medicine, 12, 708-712. https://doi.org/10.1111/j.1464-5491.1995.tb00574.x

[22] Islam, N., Akhter, J., Kayani, N. and Khan, M.A. (1993) Fructosamine: An Alternative Assessment of Past Glycaemic Control in Developing Countries. Journal of the Pakistan Medical Association, 43, 238-240.

[23] Aliyu, Z.Y., Gordeuk, V., Sachdev, V., Babadoko, A., Mamman, A.I., Akpanpe, P., Attah, E., Suleiman, Y., Aliyu, N., Yusuf, J., Mendelsohn, L., Kato, G.J. and Gladwin, M.T. (2008) Prevalence and Risk Factors for Pulmonary Artery Systolic Hypertension among Sickle Cell Disease Patients in Nigeria. American Journal of Hematology, 83, 485-490. https://doi.org/10.1002/ajh.21162

[24] Misciagna, G., Logroscino, G., De Michele, G., Cisternino, A.M., Guerra, V. and Freudenheim, J.L. (2004) Fructosamine, Glycated Hemoglobin, and Dietary Carbohydrates. Clinica Chimica Acta, 340, 139-147. https://doi.org/10.1016/j.cccn.2003.10.024

[25] Hillier, T.A., Pedula, K.L., Vesco, K.K., Schmidt, M.M., Mullen, J.A., LeBlanc, E.S. and Pettitt, D.J. (2008) Excess Gestational Weight Gain: Modifying Fetal Macrosomia Risk Associated with Maternal Glucose. Obstetrics \& Gynecology, 5, 1007-1014. https://doi.org/10.1097/AOG.0b013e31818a9779

[26] Hillier, T.A., Pedula, K.L., Schmidt, M.M., Mullen, J.A., Charles, M.A. and Pettitt, D.J. (2007) Childhood Obesity and Metabolic Imprinting: the Ongoing Effects of Maternal Hyperglycemia. Diabetes Care, 30, 2287-2292. https://doi.org/10.2337/dc06-2361

[27] Gillman, M.W., Oakey, H., Baghurst, P.A., Volkmer, R.E., Robinson, J.S. and Crowther, C.A. (2010) Effect of Treatment of Gestational Diabetes Mellitus on Obesity in the Next Generation. Diabetes Care, 33, 964-968. https://doi.org/10.2337/dc09-1810

[28] Singla, M., Ahuja, A. and Juneja, S.K. (2016) Maternal and Fetal Outcomes in Gestational Diabetes Mellitus. Journal of Evolution of Medical and Dental Sciences, 5 , 6239-6241. https://doi.org/10.14260/jemds/2016/1410

[29] Kc, K., Shakya, S. and Zhang, H. (2015) Gestational Diabetes Mellitus and Macrosomia: A Literature Review. Annals of Nutrition and Metabolism, 66, 14-20. https://doi.org/10.1159/000371628

[30] Kerényi, Z., Tamás, G., Kivimäki, M., Péterfalvi, A., Madarász, E., Bosnyák, Z. and Tabák, A.G. (2009) Maternal Glycemia and Risk of Large-for-Gestational-Age Babies in a Population-Based Screening. Diabetes Care, 32, 2200-2205. https://doi.org/10.2337/dc09-1088

[31] Kitzmiller, J.L., Cloherty, J.P., Younger, M.D., Tabatabaii, A., Rothchild, S.B., Sosenko, I., Epstein, M.F., Singh, S. and Neff, R.K. (1978) Diabetic Pregnancy and Perinatal Morbidity. American Journal of Obstetrics \& Gynecology, 131, 560-580. https://doi.org/10.1016/0002-9378(78)90120-5

[32] Mannan, J., Bhatti, M.T. and Kamal, K. (1996) Outcome of Pregnancies in Diabetic Mothers: A Descriptive Study. Pakistan Journal of Obstetrics and Gynaecology, 9, 35-40. 
[33] American Diabetes Association (2004) Standards of Medical Care in Diabetes. Diabetes Care, 27, S15-S35. https://doi.org/10.2337/diacare.27.2007.S15

[34] Makris, K. and Spanou, L. (2011) Is There a Relationship between Mean Blood Glucose and Glycated Hemoglobin? Journal of Diabetes Science and Technology, 5, 1572-1583. https://doi.org/10.1177/193229681100500634

[35] Sultanpur, C.M., Deepa, K. and Kumar, S.V. (2010) Comprehensive Review on HbAlc in Diagnosis of Diabetes Mellitus. International Journal of Pharmaceutical Sciences Review and Research, 3, 119-122.

[36] Kilpatrick, E.S., Maylor, P.W. and Keevil, B.G. (1998) Biological Variation of Glycated Hemoglobin. Implications for Diabetes Screening and Monitoring. Diabetes Care, 21, 261-264. https://doi.org/10.2337/diacare.21.2.261

[37] Macdonald, D.R., Hanson, A.M., Holland, M.R. and Singh, B.M. (2008) Clinical Impact of Variability in $\mathrm{HbA1c}$ as Assessed by Simultaneously Measuring Fructosamine and Use of Error Grid Analysis. Annals of Clinical Biochemistry, 45, 421-425. https://doi.org/10.1258/acb.2008.007259 